\title{
Bacterial profile and drug susceptibility pattern of urinary tract infection in pregnant women at University of Gondar Teaching Hospital, Northwest Ethiopia
}

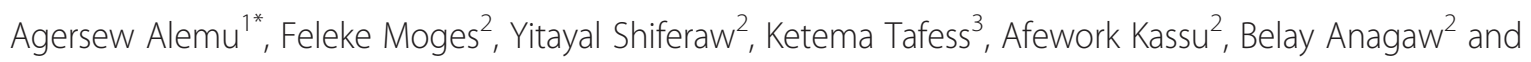
Abebe Agegn ${ }^{2}$

\begin{abstract}
Background: Urinary tract infection (UTI) is a common health problem among pregnant women. Proper investigation and prompt treatment are needed to prevent serious life threatening condition and morbidity due to urinary tract infection that can occur in pregnant women. Recent report in Addis Ababa, Ethiopia indicated the prevalence of UTI in pregnant women was $11.6 \%$ and Gram negative bacteria was the predominant isolates and showed multi drug resistance. This study aimed to assess bacterial profile that causes urinary tract infection and their antimicrobial susceptibility pattern among pregnant women visiting antenatal clinic at University of Gondar Teaching Hospital, Northwest Ethiopia.
\end{abstract}

Methods: A cross-sectional study was conducted at University of Gondar Teaching Hospital from March 22 to April 30, 2011. Mid stream urine samples were collected and inoculated into Cystine Lactose Electrolyte Deficient medium (CLED). Colony counts yielding bacterial growth of $10^{5} / \mathrm{ml}$ of urine or more of pure isolates were regarded as significant bacteriuria for infection. Colony from CLED was sub cultured onto MacConkey agar and blood agar plates. Identification was done using cultural characteristics and a series of biochemical tests. A standard method of agar disc diffusion susceptibility testing method was used to determine susceptibility patterns of the isolates.

Results: The overall prevalence of UTI in pregnant women was $10.4 \%$. The predominant bacterial pathogens were Escherichia coli $47.5 \%$ followed by coagulase-negative staphylococci $22.5 \%$, Staphylococcus aureus $10 \%$, and Klebsiella pneumoniae $10 \%$. Gram negative isolates were resulted low susceptibility to co-trimoxazole (51.9\%) and tetracycline (40.7\%) whereas Gram positive showed susceptibility to ceftriaxon (84.6\%) and amoxicillinclavulanic acid (92.3\%). Multiple drug resistance (resistance to two or more drugs) was observed in $95 \%$ of the isolates.

Conclusion: Significant bacteriuria was observed in asymptomatic pregnant women. Periodic studies are recommended to check the outcome of asymptomatic bacteriuria and also monitor any changes in the susceptibility patterns of urinary tract pathogens in pregnant women.

\footnotetext{
* Correspondence: agersewalemu@yahoo.com

'Department of Medical Parasitology, School of Biomedical and Laboratory Sciences, College of Medicine and Health Sciences, University of Gondar, Gondar, Ethiopia

Full list of author information is available at the end of the article
} 


\section{Background}

In the female human subject, the urinary tract has an important relationship with the reproductive organs because of its proximity. In the non-pregnant state, the uterus lies just behind and partly over the bladder while in the pregnant state the enlarging uterus affects all the tissues of the urinary tract at various times [1]. Urinary Tract Infection (UTI) has become the most common hospital-acquired infection, accounting for as many as $35 \%$ of nosocomial infections, and it is the second most common cause of bacteraemia in hospitalized patients [2]. Urinary tract infection accounts for a significant part of the work load in clinical microbiology laboratories and enteric bacteria remained the most frequent cause of UTI, although the distribution of pathogens that cause UTI is changing [2].

Urinary tract infection is a common health problem among pregnant women [1]. This usually begins in week 6 and peaks during weeks 22 to 24 of pregnancy due to a number of factors including urethral dilatation, increased bladder volume and decreased bladder tone, along with decreased urethral tone which contributes to increased urinary stasis and ureterovesical reflux and up to $70 \%$ of pregnant women develop glycosuria, which encourages bacterial growth in the urine [3].

UTI may manifest as asymptomatic bacteriuria (ASB) or symptomatic bacteriuria (SB). The prevalence of asymptomatic UTI has been previously reported to be $2 \%$ to $13 \%$ in pregnant women [4-6] compared with that of symptomatic UTI which accounts 1-18 \% during pregnancy [7]. The highest incidence of urinary tract infection occurs in the child bearing age and this has been linked to sexual activity and aging [8]. The predominant organisms that cause UTIs during pregnancy are $E$. coli which account for $80 \%-90 \%$ of infection $[9,10]$.

Treatment of asymptomatic bacteriuria offers no benefit for most healthy an elderly or adult non pregnant women [11]. However, screening and treatment of asymptomatic bacteriuria should be performed in pregnant women [12]. Treatment of UTI in pregnancy is of paramount importance for mother and child. Given the close association between ASB and obvious UTI, screening and treatment of ASB in pregnancy may also help to reduce adverse outcome for the child such as pre-term labour and low birth weight [12]. However, Antibiotic resistance of urinary tract pathogens has been known to increase worldwide, especially to commonly used antimicrobials [13] and pattern of antibiotic resistance in a wide variety of pathogenic organisms may vary over short periods and depend on site of isolation and different environmental conditions [14].

In many hospitals in developing countries including Ethiopia, routine urine culture test is not carried out for antenatal patients instead many clinicians choose for the strip urinalysis method for assessing urine in pregnant women. The true picture of such urine specimen cannot be fully assessed as the strip cannot quantify the extent of infection in such a patient as well as provide antimicrobial therapy which is usually seen in the case of culture test. Antibiotics are usually given empirically before the laboratory results of urine culture are available. To ensure appropriate therapy, current knowledge of the organism that causes UTIs and their antibiotic susceptibility pattern is mandatory. Therefore, periodic evaluation of antibacterial activity is needed to update information. Therefore, to readdress this situation, this study was aimed to isolate and identify the bacterial etiologic agents, including their antibiotic susceptibility pattern isolated from pregnant women with urinary tract infection visiting University of Gondar Teaching Hospital, Northwest Ethiopia.

\section{Methods}

\section{Study design and area}

A cross sectional study was conducted at the University of Gondar Teaching Hospital from March 22 to April 30, 2011. Gondar is located 738 Kilo meter far from Addis Ababa (the capital city) to the Northwest Ethiopia. The University Hospital is one of the biggest tertiary level referral and teaching hospitals in the region that provides services to over 5 million inhabitants in the Northwest Ethiopia.

\section{Study populations}

The study population was those pregnant women attending antenatal clinic (ANC) at University of Gondar Teaching Hospital during the study period and who did not initiate of antibiotics therapy during the last two weeks and during data collection.

\section{Sample size and sampling techniques Sample size determination}

A single proportion formula was used to calculate the sample size, $n=Z^{2} p(1-p) / d^{2}$. Where: $Z=Z$ score for $95 \%$ confidence interval $=1.96, \mathrm{p}=$ prevalence, $\mathrm{d}=$ tolerable error $=5 \%$. Prevalence of $50 \%$ was considered since the prevalence of UTI in pregnant women is not determined in the study area. There by $n=(1.96)^{2} 0.5(1-0.5) /(0.05)^{2}=385$, giving the final sample size of 385 .

\section{Sampling methods}

The list of all pregnant women was obtained from antenatal clinic (ANC). Study participants were selected using random systematic sampling technique taking every $n+1$ starting from serial number one.

\section{Inclusion criteria}

All pregnant women without current antibiotics therapy and welling to participate were included. 


\section{Exclusion criteria}

Pregnant women with current antibiotics therapy were excluded from the study.

\section{Sample collection and processing Sample collection}

Three hundred eighty five early morning $5 \mathrm{ml}$ of midstream urine specimens were collected using lick proof re-usable plastic containers. All of the specimens were analyzed within an hour of collection. Socio-demographic variables (Age, Sex, Marital status, Education level, Occupation, Residence and other relevant clinical data such as Parity, Gravidity, Trimester, History of catheterization, History of UTI) were obtained using a pre-designed questionnaire.

\section{Bacteriological investigation Culture}

Using calibrated wire loop $(0.001 \mathrm{ml})$ samples were inoculated in to Cystine Lactose Electrolyte Deficient medium (CLED). After overnight incubation at $37^{\circ} \mathrm{C}$ for $24-48$ hours colonies were counted to check significant growth. Colony counts yielding bacterial growth of $10^{5} / \mathrm{ml}$ of urine were regarded as significant for bacteriuria. Colonies from CLED were sub cultured into MacConkey agar and blood agar plates (BAP) (Oxoid, LTD) and incubated at $37^{\circ} \mathrm{C}$ for 24-48 hours. Identification of bacteria was done using colony characteristics, gram reaction of the organisms and biochemical test following standard procedure [15]. All procedures were conducted in University of Gondar Teaching Hospital Microbiology Laboratory by the same senior laboratory technologist in all the time to avoid professional biases.

\section{Antimicrobial susceptibility testing}

Susceptibility testing was performed on all isolates according to the criteria of National Committee for Clinical Laboratory Standards (NCCLs) [16].The drugs that were tested include amoxicillin $(10 \mu \mathrm{g})$, amoxicillinclavulinic acid $(20 \mu \mathrm{g})$, ampicillin $(30 \mu \mathrm{g})$, ciprofloxacin $(5 \mu \mathrm{g})$, Norfloxacin $(10 \mu \mathrm{g})$, gentamicin $(10 \mu \mathrm{g})$, tetracycline $(30 \mu \mathrm{g})$, co-trimoxazole $(25 \mu \mathrm{g})$ chloroamphenicol $(30 \mu \mathrm{g})$ and ceftriaxon $(10 \mu \mathrm{g})$.

\section{Quality control}

Culture media were tested for sterility and performance. Standard strains of E. coli ATCC 25922 and S. aureus ATCC 25923 were used during culture and antimicrobial susceptibility testing.

\section{Data management and analysis}

Data were entered into a database designed using MS Excel spreadsheet and analyzed using SPSS statistical software package (version 16). Study findings were explained in words and tables. Proportions for categorical variables were compared using chi-square test. In all cases P-value less than 0.05 was taken as statistically significant.

\section{Ethical considerations}

An ethical approval was obtained from ethical clearance committee of College of Medicine and Health Sciences, University of Gondar. Informed written consent was obtained from the study participants. Participants were given a full right to continue or withdraw from the study. For each confirmed infection case, the responsible clinician of the participant was informed and treatment was started as per the culture result and drug susceptibility pattern. Information obtained at each course of the study was kept confidential. Those identified positive for bacteriuria during the study period were referred to attending physicians and treated by appropriate drugs in line with the national guidelines for treatment of pregnant women.

\section{Results}

\section{Sociodemographic characteristics}

A total of 385 pregnant women were enrolled in this study with the age ranges of 17-45 years with the mean (standard deviation) of $26( \pm 5.3)$ years. Among the study subjects, 383 (99.5\%) were married. Two hundred ten $(54.5 \%)$ had educational level of secondary and above and $338(87.8 \%)$ were urban dwellers. Based on their parity, 144 (37.4\%), 83 (21.6\%), and 158 (41\%) were nulliparous, monoparous, multiparous, respectively. Whereas, 168 (43.7\%), 166 (43.1\%) and 51 (13.2\%) of study subjects were in the $3^{\text {rd }}, 2^{\text {nd }}$ and $1^{\text {st }}$ trimester of pregnancy. Thirteen $(3.4 \%)$ and $47(12.2 \%)$ of study subjects had history of previous catheterization and urinary tract infection, respectively (Table 1).

\section{Prevalence of urinary tract infection}

The overall prevalence of UTI was $10.4 \%$. Of all considered variables only history of catheterization and previous history of UTI were significantly associated with UTI. Out of 40 pregnant women who had significant bacteriuria, 13 $(32.5 \%)$ had a history of UTI in their pregnancy and received antibiotic for that UTI $(\mathrm{P}=0.001)$, and $5(12.5 \%)$ had a history of catheterization $(\mathrm{P}=0.001)$. There was no association between maternal age, address, parity, gravidity, trimester, occupation, marital status and education with bacteriuria (Table1).

\section{Isolation and identification of bacterial uropathogens} Of all the bacteria isolated $(n=40)$, Gram-negative bacteria were more prevalent 27 (67.5 \%) than Gram-positive bacteria 13 (32.5\%). The most commonly isolated bacteria were $E$. coli 19 (47.5\%), followed by coagulase negative Staphylococci 9 (22.5\%), S. aureus and K. pneumoniae 
Table 1 Prevalence of UTI and demographic characteristic of study population $(\mathrm{N}=385)$ at Gondar University Hospital, March 22 to April 30, 2011

\begin{tabular}{|c|c|c|c|c|c|}
\hline Characteristics & $\begin{array}{l}\text { No. } \\
\text { Tested } \\
(\%)\end{array}$ & $\begin{array}{c}\text { No. } \\
\text { negative } \\
\text { (\%) }\end{array}$ & $\begin{array}{l}\text { No. } \\
\text { Positive } \\
\text { (\%) }\end{array}$ & $\begin{array}{c}\text { Chi-square } \\
\left(x^{2}\right)\end{array}$ & P-value \\
\hline
\end{tabular}

Age(years)

16-20

$21-25$

26-30

31-35

$36-40$

41-45

71(18.4) 63(88.7) $8(11.3)$

128(33.3) 115(89.8) 13(10.2)

132(34.3) 119(90.2) 13(9.8)

1.840

0.871

32(8.3) 29(90.6) 3(9.4)

19(4.9) 17(89.5) 2(10.5)

Address

Urban

$3(0.8)$

2(66.7)

1(33.3)

Marital status

Married

$\begin{array}{ccc}338(87.8) & 303(89.6) & 35(10.4) \\ 47(12.2) & 42(89.4) & 5(10.6)\end{array}$

0.004

0.952

Other

383(99.5)

343(89.6)

$40(10.4)$

0.233

0.629

Educational status

\begin{tabular}{|c|c|c|c|c|c|}
\hline Illiterate & $67(17.4)$ & 64(95.6) & $3(4.5)$ & & \\
\hline Primary(1-8) & $108(28.1)$ & 96(88.9) & $12(11.1)$ & 3.503 & 0.320 \\
\hline Secondary(9-12) & 140(36.4) & $122(87.1)$ & 18(12.9) & & \\
\hline Higher $>12$ & $70(18.1)$ & 63(90) & $7(10)$ & & \\
\hline \multicolumn{6}{|l|}{ Symptom of UTI } \\
\hline Yes & $85(22.1)$ & $72(84.7)$ & 13(15.3) & 2.818 & 0.093 \\
\hline No & $300(77.9)$ & 273(91) & $27(9)$ & & \\
\hline \multicolumn{6}{|l|}{ Gravidity } \\
\hline $1-3$ & $324(84.2)$ & 291(89.8) & $33(10.2)$ & & \\
\hline $4-6$ & $47(12.2)$ & $42(89.4)$ & $5(10.6)$ & 0.482 & 0.923 \\
\hline $7-9$ & $13(3.4)$ & $11(84.6)$ & $2(15.4)$ & & \\
\hline$>9$ & $1(.2)$ & $1(100)$ & $0(0)$ & & \\
\hline \multicolumn{6}{|l|}{ Parity } \\
\hline Nullipara & 144(37.4) & 131(91) & 13(9) & & \\
\hline One & $83(21.6)$ & 75(99.4) & $8(9.6)$ & 0.791 & 0.673 \\
\hline Multipara & $158(41)$ & 139(88) & $19(12)$ & & \\
\hline \multicolumn{6}{|l|}{ Trimester } \\
\hline $1^{\text {st }}$ & $51(13.2)$ & $50(98)$ & $1(2)$ & & \\
\hline $2^{\text {nd }}$ & $166(43.1)$ & 148(89.2) & 18(10.8) & 4.732 & 0.094 \\
\hline $3^{\text {rd }}$ & 168(43.6) & $147(87.5)$ & $21(12.5)$ & & \\
\hline \multicolumn{6}{|c|}{ History of catheterization } \\
\hline Yes & $13(3.4)$ & $8(61.5)$ & $5(38.4)$ & 11.388 & 0.001 \\
\hline No & 372(96.6) & 337(90.6) & $35(9.4$ & & \\
\hline \multicolumn{6}{|l|}{ History of UTI } \\
\hline Yes & $47(12.2)$ & $34(72.3)$ & $13(6.4)$ & 17.150 & 0.001 \\
\hline No & 338(87.8) & $311(92)$ & $27(8)$ & & \\
\hline
\end{tabular}

4. (10 \%) each. Enterobacter aerogenes and Morganella morgani accounts, 2 (5 \%) each (Table 2).

\section{Antimicrobial susceptibility pattern of bacterial uropathogens}

The result of antimicrobial susceptibility pattern of the isolate is shown on Tables 3 and 4 below. Rates of susceptibility of Gram-negatives range from $0 \%-100 \%$. All isolates were sensitive to chloramphenicol 27 (100\%). Most of Gram-negative isolates were sensitive to ceftriaxon 26 (96.3\%), ciprofloxacin 26 (96.3\%), norfloxacin 25 (92.6\%), gentamicin 25 (92.6\%), amoxicillin-clavulanic acid 16 (59.3\%), co-trimoxazole 14 (51.9\%), and tetracycline 11 (40.7\%). However, all solates of gram-negetive bacteria were were resistance to ampicillin, and amoxacillin 27 (100\%). Among the Gram negatives, the predominant isolate was E. coli, 19 (70.4 \% of the Gram-negatives, $47.5 \%$ of all isolate) demonstrated high level of resistance to ampicillin and amoxacillin 19 (100\%) followed by tetracycline 10 (52.6\%). All isolates of E.coli were sensitive to ceftriaxon, chloramphenicol, ciprofloxacin and norfloxacin 19 (100 \%), followed by gentamicin 18 (94.7 \%) (Table 3).

Majority of Gram positives were resistant to most of the antibiotics tested than the Gram negatives. As indicated on Table 4, the rates of susceptibility of Gram- positives range from $20 \%-90 \%$. Among the Gram-positives, 11 (84.6\%), $12(92.3 \%)$ and $12(92.3 \%)$ of the isolates were sensitive to ceftriaxon, gentamicin and amoxicillin-clavulanic acid respectively. Coagulase negative staphylococci, which were the predominant isolates from Gram-positives 9 (69.2\%), were resistance to most of the antibiotics tested. Their resistance patterns of the isolates were found to be 8 (88.9\%) for ampicillin, 7 (77.9\%) for co-trimoxazol and tetracycline, and 6 (66.7 \%) for amoxacillin and chloramphenicol. Gentamicin and amoxicillin -clavulanic were found to be effective against 8 (88.9\%) coagulase negative staphylococci (Table 4).

\section{Multiple drug resistance patterns of the isolates}

Among the total isolates $(n=40)$ multi drug resistance ( $\mathrm{MDR}=$ resistance in $\geq 2$ drugs) were recorded in 38 (95\%) of all bacterial uropathogens. All isolates of Gram negative bacteria and $84.6 \%$ of Gram positive bacteria showed resistance for two or more drugs (Table 5).

\section{Discussion}

The overall prevalence of urinary tract infection in pregnant women in this study was $10.4 \%$. This is comparable to the prevalence of UTI reported in Addis Ababa, Ethiopia (11.6\%) [17], but lower than study in Northern Tanzania (16.4 \%) [18], Mwanza, North-western Tanzania (14.6 \%) [19], and Khartoum North Hospital, Sudan (14.0 \%) [20]. This variation may be explained by the fact that differences 
Table 2 Frequency of bacterial uropathogens isolated from pregnant women $(\mathrm{N}=40)$ at Gondar University Hospital, March 22 to April 30, 2011

\begin{tabular}{ll}
\hline Bacterial isolates & Total (\%) \\
\hline Escherichia coli & $19(47.5)$ \\
Enterobacter aerogenes & $2(5)$ \\
Klebsiella pneumoniae & $4(10)$ \\
Morganella morgani & $2(5)$ \\
CNS & $9(22.5)$ \\
Staphylococcus aureus & $4(10)$ \\
Total & $\mathbf{4 0 ( 1 0 0 )}$ \\
\hline
\end{tabular}

${ }^{*}$ CNS = coagulase negative staphylococcus.

in the environment, social habits of the community, the standard of personal hygiene and education.

There was no association between maternal age, address, parity, gravidity, occupation, marital status and education with bacteriuria in this study. This was in agreement with studies in Tanzania [19] and Sudan [20]. Indifferent from our result other study showed that maternal age and parity have been previously observed as risk factors for UTI among pregnant women [21]. However, Closer analysis of the published literature reveals that the age and parity effects are poorly characterized. For example, some studies showed that the prevalence of UTI increased with age [22], while others found it more with a younger age group [23].

The prevalence of urinary tract infection in pregnant women with previous history of urinary tract infection was significantly higher than those without previous history $(p=0.001)$. This result agrees with research work in Pakistan [24]. This might be due to presence of resistance strains from those who had previous history of UTI. Our study also showed the prevalence of urinary tract infection in pregnant women with previous history of catheterization was significantly higher than those without history of previous catheterization $(\mathrm{P}=0.001)$. This finding agrees with previous report in Gondar [25]. This could be due to long duration of catheterization, frequent catheterization or contamination during inserting catheters.

Gram-negative bacterial isolate were more prevalent (67.5 \%) than Gram-positive bacterial isolates (32.5\%). Comparable rate of isolation of Gram-negative and Grampositive bacteria, $60 \%$ and $40 \%$, were reported in Tikur Anbessa Specialized Hospital Addis Ababa, Ethiopia [17] and $61.9 \%$ and $38.1 \%$ in Tanzania [26]. This could be due to the presence of unique structure in Gram negative bacteria which help for attachment to the uroepithelial cells and prevent bacteria from urinary lavage, allowing for multiplication and tissue invasion - resulting in invasive infection and pyelonephritis in pregnancy [9].

E. coli was the most predominant pathogen with over all isolation rates of $47.5 \%$. Comparable findings have been reported in Yemen, $41.5 \%$ [27], Nigeria, $42.1 \%$ [28], Khartoum North Hospital, Sudan 42.4\% [20], and Tikur Anbessa Specialized Hospital Addis Ababa, Ethiopia $44 \%$ [17]. E. coli is the most common microorganism in the vaginal and rectal area [29]. Because of anatomical and functional changes and difficulty of maintaining personal hygiene during pregnancy, may increase the risk of acquiring UTI from E. coli. Coagulase-negative staphylococci (CNS) were the second dominant pathogen with overall isolation rate of $22.5 \%$. Comparable findings also reported from Tikur Anbessa Specialized Hospital Addis Ababa, Ethiopia $16 \%$ [17], and Tanzania $16.7 \%$ [26].

Table 3 Antimicrobial susceptibility pattern of Gram-negative bacteria isolated from urine culture of pregnant women ( $N=27$ ) at Gondar University Hospital, March 22 to April 30, 2011

\begin{tabular}{|c|c|c|c|c|c|c|c|c|c|c|c|c|}
\hline \multirow[t]{3}{*}{ Bacterial isolate } & \multirow{3}{*}{$\begin{array}{c}\text { Total } \\
\text { No. }\end{array}$} & \multirow[t]{3}{*}{ Pattern } & \multicolumn{10}{|c|}{ Antimicrobial agents tested } \\
\hline & & & AMP & AMOX & CRO & CAF & CIP & $\mathrm{CN}$ & NOR & SXT & TTC & AMC \\
\hline & & & No.(\%) & No. (\%) & No.(\%) & No. (\%) & No. (\%) & No. (\%) & No. (\%) & No.(\%) & No. (\%) & No (\%) \\
\hline \multirow[t]{2}{*}{$\overline{\text { E. coli }}$} & 19 & $\mathrm{~s}$ & $0(0)$ & $0(0)$ & $19(100)$ & 19(100) & 19(100) & 18(94.7) & $19(100)$ & 14(73.7) & $9(47.4)$ & $12(63.2)$ \\
\hline & & $\mathrm{R}$ & 19(100) & 19(100) & $0(0)$ & $0(0)$ & $0((0)$ & $1(5.3)$ & $0(0)$ & $5(26.3)$ & 10(52.6) & $7(36.8)$ \\
\hline \multirow[t]{2}{*}{ Enterobacter aerogenes } & 2 & S & $0(0)$ & $0(0)$ & $2(100)$ & $2(100)$ & $2(100)$ & $2(100)$ & $2(100)$ & $0(0)$ & $1(50)$ & $1(50)$ \\
\hline & & R & $2(100)$ & $2(100)$ & $0(0)$ & $0(0)$ & $0(0)$ & $0(0)$ & $0(0)$ & $2(100)$ & $1(50)$ & $1(50)$ \\
\hline \multirow[t]{2}{*}{ Klebsiela pneumoniae } & 4 & S & $0(0)$ & $0(0)$ & $3(75)$ & $4(100)$ & $3(75)$ & $3(75)$ & $2(50)$ & $0(0)$ & $0(0)$ & $2(50)$ \\
\hline & & $\mathrm{R}$ & $4(100)$ & $4(100)$ & $1(25)$ & $0(0)$ & $1(25)$ & $1(25)$ & $2(50)$ & $4(100)$ & $4(100)$ & $2(50)$ \\
\hline \multirow[t]{2}{*}{ Morganella morgani } & 2 & s & $0(0)$ & $0(0)$ & $2(100)$ & $2(100)$ & $2(100)$ & $2(100)$ & $2(100)$ & $0(0)$ & $0(0)$ & $1(50)$ \\
\hline & & $\mathrm{R}$ & $2(100)$ & $2(100)$ & $0(0)$ & $0(0)$ & $0(0)$ & $0(0)$ & $\mathrm{O}(0)$ & $2(100)$ & $2(100)$ & $1(50)$ \\
\hline \multirow[t]{2}{*}{ Total } & 27 & S & $0(0)$ & $0(0)$ & $26(96.3)$ & $27(100)$ & $26(96.3)$ & $25(92.6)$ & $25(92.6)$ & 14(51.9) & $11(40.7)$ & $16(59.3)$ \\
\hline & & $\mathbf{R}$ & $27(100)$ & $27(100)$ & $1(3.7)$ & $0(0)$ & $1(3.7)$ & $2(7.4)$ & $2(7.4)$ & $13(48.1)$ & $16(59.3)$ & $11(40.7)$ \\
\hline
\end{tabular}

$\overline{\mathbf{A M P}}=$ ampicillin $\mathbf{C A F}=$ chloramphenicol $\mathbf{N O R}=$ norfloxacin. 
Table 4 Antimicrobial susceptibility pattern of Gram-positive bacteria isolated from urine culture of pregnant women ( $N=13$ ) at Gondar University Hospital, March 22 to April 30, 2011

\begin{tabular}{|c|c|c|c|c|c|c|c|c|c|c|c|c|}
\hline \multirow{2}{*}{$\begin{array}{l}\text { Bacterial } \\
\text { isolate }\end{array}$} & \multirow{2}{*}{$\begin{array}{l}\text { Total } \\
\text { No. }\end{array}$} & \multirow{2}{*}{ Pattern } & \multicolumn{10}{|c|}{ Antimicrobial agents tested } \\
\hline & & & AMP & AMOX & CRO & CAF & CIP & CN & NOR & $\begin{array}{c}\text { SXT } \\
\end{array}$ & TTC & $\begin{array}{c}\text { AMC } \\
\text { No }(\%)\end{array}$ \\
\hline \multirow[t]{2}{*}{ CNS } & 9 & $S$ & $1(11.1)$ & $3(33.3)$ & $7(77.8)$ & $3(33.3)$ & $5(55.6)$ & $8(88.9)$ & $5(55.6)$ & $2(22.2)$ & $2(22.2)$ & $8(88.9)$ \\
\hline & & $\mathrm{R}$ & 8(88.9) & $6(66.7)$ & $2(22.2)$ & $6(66.7)$ & $4(44.4)$ & $1(11.1)$ & $4(44.4)$ & $7(77.8)$ & $7(77.8)$ & $1(11.1)$ \\
\hline \multirow[t]{2}{*}{ S.aureus } & 4 & S & $1(25)$ & $2(50)$ & $4(100)$ & 2(50) & $3(75)$ & $4(100)$ & $2(50)$ & $2(50)$ & $1(25)$ & $4(100)$ \\
\hline & & $\mathrm{R}$ & $3(75)$ & $2(50)$ & $0(0)$ & $2(50)$ & 1(25) & $0(0)$ & $2(50)$ & $2(50)$ & $3(75)$ & $0(0)$ \\
\hline \multirow[t]{2}{*}{ Total } & 13 & $S$ & $2(15.4)$ & $5(38.5)$ & $11(84.6)$ & $5(38.5)$ & $8(61,5)$ & 12(92.3) & $7(53.8)$ & $4(30.8)$ & $3(23.1)$ & $12(92.3)$ \\
\hline & & R & $11(84.6)$ & $8(61.5)$ & $2(15.4)$ & $8(61.5)$ & $5(38.5)$ & $1(7.7)$ & $6(46.2)$ & $9(69.2)$ & $10(76.9)$ & $1(7.7)$ \\
\hline
\end{tabular}

$\overline{\mathrm{AMP}}=$ ampicillin $\mathrm{CAF}=$ chloramphinicol $\mathrm{NOR}=$ norfloxacin .

AMOX = amoxacillin CIP = ciprofloxacin SXT = co-trimoxazole.

CRO = ceftriaxon $\mathrm{CN}=$ gentamicin $\mathrm{TTC}=$ tetracycline.

$\mathrm{AMC}=$ amoxicilin + clavulinic acid.

Antimicrobial resistance among uropathogens to the commonly used antibiotics become increasing that make clinicians with very few choices of drugs for the treatment of urinary tract infection $[17,30]$. In this study, susceptibility pattern of Gram-negative bacteria showed that most of the isolates were sensitive to chloramphenicol (100\%), ceftriaxon $(96.3 \%)$, ciprofloxacin $(96.3 \%)$, gentamicin (92.6), norfloxacin (92.6), amoxicillin-clavulanic acid (59.3\%), co-trimoxazole (51.9 \%), and tetracycline (40.7 \%). In contrary, a study in Tikur Anbessa Specialized Hospital Addis Ababa, Ethiopia [17] indicated that the susceptibility pattern for Gram-negative bacteria were amoxicillin-clavulanic acid (70\%), chloramphenicol (83.3\%), gentamicin (93.3\%) and co-trimoxazole (73.3\%). The easy availability and indiscriminate use of commonly used drugs such as co-trimoxazole and tetracycline may lead to an increase to resistance.

Among Gram-positive bacteria tested for the available drugs, some of the isolates showed susceptibility of (92.3\%), $(92.3 \%)$ and $(84.6 \%)$, to amoxicillin-clavulanic acid, gentamicin, and ceftriaxon, respectively. This is not in line with the report in Tikur Anbessa Specialized Hospital Addis Ababa, Ethiopia [17] which reported sensitivity of $100 \%$ to amoxicillin-clavulanic acid and $85 \%$ to gentamicin. In this study the effectiveness of amoxicillin-clavulanic acid to Gram-positive bacteria is reduced from comparable study. This may be explained as amoxicillin-clavulanic acid may be used for empiric therapy.

Multi drug resistance (MDR = resistance in $\geq 2$ drugs) was seen in $95 \%$ of the isolated bacterial uropathogens. A lower finding was reported in Tikur Anbessa Specialized Hospital Addis Ababa, Ethiopia 74 \% [17].This indicates that multi drug resistance was found to be very high to the commonly used antibiotics. Antibiotic resistance has been recognized as the consequence of antibiotic use and abuse [31]. Therefore, the reasons for this alarming phenomenon might be inappropriate and incorrect administration of antimicrobial agents in empiric therapies and lack of appropriate infection control strategies, which can cause a shift to increase prevalence of resistant organism in the community.

\section{Conclusion}

In the current study, the overall prevalence of asymptomatic UTI was $10.4 \%$. UTI prevalence was positively associated with previous history of catheterization and UTI. E. coli were the most predominant organisms followed by

Table 5 Multi drug resistance pattern of bacterial isolates of pregnant women $(\mathrm{N}=\mathbf{4 0})$ at Gondar University Hospital, March 22 to April 30, 2011

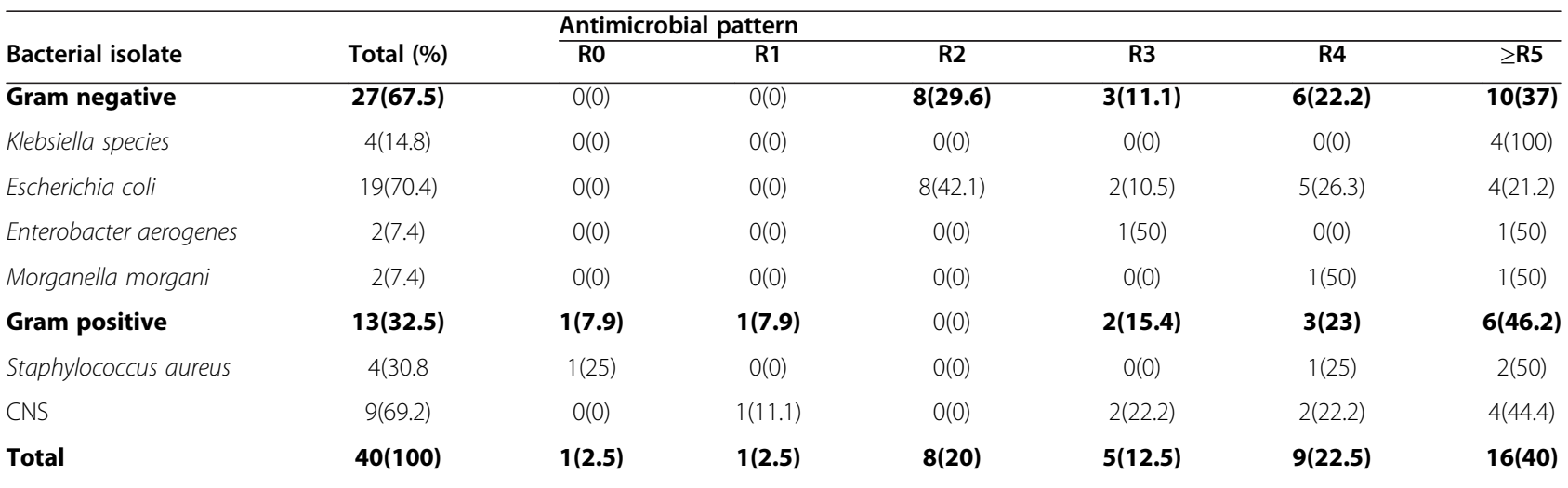


coagulase negative staphylococci and most of the bacterial isolates were sensitive to gentamicin, ceftriaxon, ciprofloxacin, norfloxacin, and chloroamphenicol. A large number of the isolates were resistant to ampicillin, amoxacillin, tetracycline, and co-trimoxazole. Multi-drug resistance bacteria were common. Periodic and continuous follow up are mandatory to reduce the consequence of asymptomatic bacteriuria and multi-drug resistance bacteria in pregnancy.

\section{Competing interests}

The authors declare that they have no competing interests.

\section{Acknowledgments}

We would like to express deepest gratitude to study subjects, all staff members of University of Gondar Hospital Laboratory and Antenatal clinic.

\section{Author details}

'Department of Medical Parasitology, School of Biomedical and Laboratory Sciences, College of Medicine and Health Sciences, University of Gondar, Gondar, Ethiopia. ${ }^{2}$ Department of Medical Microbiology, School of Biomedical and Laboratory Sciences, College of Medicine and Health Sciences, University of Gondar, Gondar, Ethiopia. ${ }^{3}$ Department of Immunology and Molecular Biology, School of Biomedical and Laboratory Sciences, College of Medicine and Health Sciences, University of Gondar, Gondar, Ethiopia.

\section{Authors' contributions}

AA was the primary researcher, conceived the study, designed, participated in data collection, conducted data analysis, drafted and finalized the manuscript for publication. FM, KT, YS and AK assisted in data collection and reviewed the initial and final drafts of the manuscript. AA, FM, YS and BA interpreted the results, and reviewed the initial and final drafts of the manuscript. All authors read and approved the final manuscript.

Received: 9 February 2012 Accepted: 25 April 2012

Published: 25 April 2012

\section{References}

1. Mittal P, Wing DA: Urinary tract infections in pregnancy. Clin Perinatol 2005, 32:749-7641

2. Epoke CO, Anyanwu GO, Opara AA: The Prevalence of Significant Bacteriuria in Diabetic Patients. Diabetic International 2000, 10:16-17.

3. Van Brummen HJ, Bruinse HW, van der Bom JG, Heintz AP, van der Vaart CH: How do the prevalences of urogenital symptoms change during pregnancy? Neurourol Urodyn 2006, 25:135-139.

4. Delzell JE Jr, Lefevre ML: Urinary tract infections during pregnancy. Am Fam Physician 2000, 61:713-721.

5. Christensen B: Which antibiotics are appropriate for treating bacteriuria in pregnancy? J Antimicrob Chemother 2000, 46:29-34.

6. Kutlay S, Kutlay B, Karaahmetoglu O, Ak C, Erkaya S: Prevalence, detection and treatment of asymptomatic bacteriuria in a Turkish obstetric population. J Reprod Med 2003, 48:627-630.

7. Abdullah AA, Al-Moslih MI: Prevalence of asymptomatic bacteriuria in pregnant women in Sharjah, United Arab Emirates. East Mediterr Health J 2005, 11:5-6.

8. Okonko IO, ljandipe LA, llusanya AO, Donbraye-Emmanuel OB, Ejembi J, Udeze AO, Egun OC, Fowotade A, Nkang AO: Incidence of urinary tract infection (UTI) among pregnant women in Ibadan, South-Western Nigeria. Afr J Biotechnol 2009, 8:6649-6652.

9. Amiri FN, Rooshan MH, Ahmady MH, Soliamani MJ: Hygiene practices and sexual activity associated with urinary tract infection in pregnant women. East Mediterr Health J 2009, 15:105-108.

10. Mincey BA, Parkulo MA: Antibiotic prescribing practices in a teaching clinic: comparison of resident and staff physicians. South Med J 2001, 94:365-369.

11. Lentz G: Urinary Tract Infections in Obstetrics and Gynecology. In Global Library of Women's medicine. University of Washington. Seattle: Washington USA; 2009.
12. Nicolle LE: Asymptomatic bacteriuria: review and discussion of the IDSA guidelines. Int J Antimicrob Agents 2006, 28:42-48.

13. Kahlmeter $\mathrm{G}$ : An international survey of the antimicrobial susceptibility of pathogens from uncomplicated urinary tract infections; the ECO, SENS Projects. Journal of Antimicrobials chemotherapy 2003, 51:69-71.

14. Gupta K, Hooten TM, Stamm WE: Increasing antimicrobial resistance and the management of uncomplicated community-acquired urinary tract infections. Ann Intern Med 2001, 135:41-50.

15. Cheesbrough M: Biochemical tests to identify bacteria. In District Laboratory Practice in Tropical Countries, Part 2. Cambridge. UK: Cambridge University Press; 2000:63-70.

16. National Committee for Clinical Laboratory Standards. Performance standards of antimicrobial susceptibility. NCCLS approved standard M100-59 National Committee for clinical Laboratory Standard, Wayne. PA, 2002.

17. Assefa A, Asrat D, Woldeamanuel $Y, G /$ Hiwot $Y$, Abdella A, Melesse $T$ : Bacterial profile and drug susceptibility pattern of urinary tract infection in pregnant women at Tikur Anbessa Specialized Hospital Addis Ababa, Ethiopia. Ethiopia Medical Journal 2008, 46:227-235.

18. Olsen BE, Hinderaker SG, Lie RT, Gasheka P, Baerheim A, Bergsjo P, Kvale G: The diagnosis of urinary tract infections among pregnant women in rural Tanzania; Prevalence and correspondence between different diagnostic methods. Acta Obstetrica Gynecology Scandinavia 2000, 79:729-736.

19. Masinde A, Gumodoka B, Kilonzo A, Mshana SE: Prevalence of urinary tract infection among pregnant women at Bugando Medical Centre, Mwanza, Tanzania. Tanzan J Health Res 2009, 11:154-159.

20. Hamdan Z, Ziad Abdel Haliem M, Ali Salah K, Ishag Adam: Epidemiology of urinary tract infections and antibiotics sensitivity among pregnant women at Khartoum North Hospital. Ann Clin Microbiol Antimicrob 2011, $10: 2-5$.

21. Haider G, Zehra N, Munir AA, Haider A: Risk factors of urinary tract infection in pregnancy. J Pak Med Assoc 2010, 60:213-216.

22. Tugrul S, Oral O, Kumru P, Kose D, Alkan A, Yildirim G: Evaluation and importance of asymptomatic bacteriuria in pregnancy. Clin Exp Obstet Gynecol 2005, 32:237-240.

23. Moghadas AJ, Irajian G: Asymptomatic urinary tract infection in pregnant women. Iran Journal of Patholology 2009, 4:105-108.

24. Sheikh, Khan MS, Khatoon A, Arain GM: Incidence of urinary tract infection during pregnancy. East Mediterr Health J 2000, 6:265-271.

25. Moges F, Mengistu G, Genetu A: Multiple drug resistance in urinary pathogens at Gondar College of Medical Sciences Hospital, Ethiopia. East Africa Medical Journal 2002, 79:415-419.

26. Sabrina J, Said A, Mabula K, Samuel Y: Bacterial isolates and drug susceptibility patterns of urinary tract infection among pregnant women at Muhimbili National Hospital in Tanzania. Journal of Health Research. 2010, 12:4-14.

27. Al-Haddad A: Urinary tract infection among pregnant women, in Al-Mukalla district, Yemen. East Mediterr Health J 2005, 11:505-510.

28. Okonko IO, ljandipe $L A$, Ilusanya $A O$, Donbraye-Emmanuel $O B$, Ejembi J, Udeze AO, Egun OC, Fowotade A, Nkang AO: Detection of Urinary Tract Infection (UTI) among pregnant women in Oluyoro Catholic Hospital, Ibadan, South-Western Nigeria. Malaysian Journal of Microbiology 2010, 6:16-24.

29. Jazayeri A, Irajian G: Asymptomatic Urinary Tract Infection in Pregnant Women. Iranian Journal of Pathology 2009, 4:105-108.

30. Mohammad M, Mahdy ZA, Omar J, Maan N, Jamil MA: Laboratory aspects of asymptomatic bacteriuria in pregnancy. Southeast Asian J Trop Med Public Health 2002, 33:575-580.

31. Albrich WC, Monnet DL, Harbarth S: Antibiotic selection pressure and resistance in Streptococcus pneumoniae and Streptococcus pyogenes. Emerging Infectious Disease 2004, 38:363-371.

doi:10.1186/1756-0500-5-197

Cite this article as: Alemu et al: Bacterial profile and drug susceptibility pattern of urinary tract infection in pregnant women at University of Gondar Teaching Hospital, Northwest Ethiopia. BMC Research Notes 2012 5:197. 